\title{
Estimation of diffuse photosynthetically active radiation and the spatiotemporal variation analysis in China from 1981 to 2010
}

\author{
REN Xiaoli ${ }^{1,2}$, HE Honglin ${ }^{1}$, 'ZHANG Li ${ }^{1}$, YU Guirui ${ }^{1}$ \\ 1. Key Laboratory of Ecosystem Network Observation and Modeling, Institute of Geographic Sciences and \\ Natural Resources Research, CAS, Beijing 100101, China; \\ 2. University of Chinese Academy of Sciences, Beijing 100049, China
}

\begin{abstract}
Photosynthetically active radiation (PAR) is the energy source of plant photosynthesis, and the diffuse component can enhance canopy light use efficiency, thereby increasing the carbon uptake. Therefore, diffuse PAR is an important driving factor of ecosystem productivity models. In this study, we estimated the diffuse PAR of over 700 meteorological sites in China from 1981 to 2010 using an empirical model based on observational data from Chinese Ecosystem Research Network (CERN) and China Meteorology Administration. Then we derived the spatial data set of $10 \mathrm{~km}$ monthly diffuse PAR using ANUSPLIN software, and analyzed the spatiotemporal variation characteristics of diffuse PAR through GIS and trend analysis techniques. The results showed that: (1) The spatial patterns of annual average diffuse PAR during 1981-2010 are heterogeneous across China, lower in the northeast and higher in the west and south. The nationwide average value for 30 years ranges from 6.66 $\mathrm{mol} \mathrm{m} \mathrm{m}^{-2} \mathrm{~d}^{-1}$ to $15.27 \mathrm{~mol} \mathrm{~m}^{-2} \mathrm{~d}^{-1}$, and the value in summer is the biggest while the value in winter is the smallest. (2) There is an evident increasing trend of annual diffuse PAR during recent 30 years, with the increasing amplitude at $0.03 \mathrm{~mol} \mathrm{~m}^{-2} \mathrm{~d}^{-1} / 10$ a. But a significant declining trend is shown in the first 10 years, and obvious anomalies can be seen in 1982, 1983, 1991 and 1992. And there is a downtrend in spring and an uptrend in all the other seasons. (3) The spatial distribution of temporal variation rates of diffuse PAR is inhomogeneous across the country, generally decreasing in the north and increasing in the south.
\end{abstract}

Keywords: photosynthetically active radiation (PAR); diffuse fraction; diffuse PAR; spatiotemporal variations

\section{Introduction}

Solar radiation is the main source of the Earth's surface energy exchanges (Wild et al., 2005;

Received: $2013-12-20$ Accepted: $2014-01-27$

Foundation: Research on the key technology of effectiveness evaluation and standardized construction of National Nature Reserve, No.201209028; "Strategic Priority Research Program-Climate Change: Carbon Budget and Relevant Issues" of the Chinese Academy of Sciences, No.XDA05050600; Key Projects in the National Science \& Technology Pillar Program during the Twelve Five-year Plan Period, No.2013BAC03B03

Author: Ren Xiaoli (1984-), PhD, E-mail: xlren_lydia@hotmail.com

"Corresponding author: Zhang Li (1982-), E-mail: li.zhang@igsnrr.ac.cn 
Wild, 2009; Sun and Zhou, 2010). The portion with wavelengths ranging from 400 to 700 $\mathrm{nm}$ is the primary energy source of vegetation photosynthesis, known as photosynthetically active radiation (PAR). In ecological modeling, PAR is an important environmental factor affecting terrestrial ecosystem productivity (Jacovides et al., 2007; Zhu et al., 2010; He et al., 2011). Generally, the photosynthesis of plant canopy enhances with the increase of PAR, when other environmental variables are not limiting. However, besides the intensity, the geometry of PAR is also important (Farquhar and Roderick, 2003). Photosynthesis is greater if two leaves receive moderate PAR than if one leaf receives excessive PAR while the other in the shade (Farquhar and Roderick, 2003). Therefore, the uniform distribution of PAR in the canopy is important (Farquhar and Roderick, 2003; Gu et al., 2003; Mercado et al., 2009; Kanniah et al., 2012). Under sunny conditions, the sunlit fraction of the canopy is often light saturated and therefore has low light-use efficiency (LUE); whereas the fraction in the shade has higher LUE but receives much less PAR. On the contrary, under cloudy conditions, the diffuse PAR coming from all directions of the sky can penetrate deeper into the canopy, thereby reducing the photosynthetic saturation and enhancing LUE of the whole canopy (Gu et al., 2002, 2003; Mercado et al., 2009; Kanniah et al., 2012). Therefore, studying the effects of diffuse PAR on ecosystem productivity has become one of the main goals in terrestrial carbon cycle researches (Gu et al., 1999, 2002, 2003; Mercado et al., 2009; Sun and Zhou, 2010; Zhang et al., 2010; He et al., 2011; Zhang et al., 2011).

In order to quantify the impact of diffuse PAR on ecosystem productivity, the explicit treatment of diffuse PAR in ecosystem models is needed (Gu et al., 2003; Mercado et al., 2009; Kanniah et al., 2012). Hence, obtaining the data of diffuse PAR and understanding its spatiotemporal variations are critical to estimate the impact on the carbon cycle of terrestrial ecosystems. Currently, there are many sites measuring PAR and diffuse radiation in China but few diffuse PAR observation sites, so the acquisition of diffuse PAR data requires estimation models. Diffuse PAR is usually estimated by multiplying PAR and diffuse fraction of global radiation, but this is only a rough estimate because the diffuse fraction of global radiation is not equivalent to the diffuse fraction of PAR. The diffuse fraction of PAR is significantly greater than that of global radiation under clear skies, while almost equivalent under cloudy skies (Spitters et al., 1986). Optical depth models (Cho et al., 2003) and spectral models (Wang et al., 2008) are more accurate, whereas it is difficult to obtain the required input data, especially at large regional scale. Spitters et al. (1986) proposed a relatively simple method to estimate diffuse PAR, which just needs PAR and diffuse fraction of global radiation as inputs. The Spitters model has been verified and applied in many sites around the world (Tsubo and Walker, 2005; Jacovides et al., 2007), indicating that this model has certain universality.

In previous studies, we have systematically explored the spatiotemporal variation characteristics of PAR and diffuse radiation in China (Zhu et al., 2010; Ren et al., 2013). Zhu et al. (2010) calculated PAR in recent 50 years, but did not give the accuracy validation. Ren et al. (2013) calculated the diffuse radiation in recent 30 years and the cross-validation results showed high estimation accuracy. This paper aims to explore the spatiotemporal variation characteristics of diffuse PAR in China based on the progress of previous studies. The flow diagram of the methodology is illustrated in Figure 1. We first verify the estimation accuracy 
of PAR, thereby achieving the accuracy verification of all the inputs of Spitters model, based on the measurement data of nationwide meteorological stations and Chinese Ecosystem Research Network (CERN). Then the diffuse PAR of China in recent 30 years is estimated using PAR and diffuse radiation data and the Spitters model, and the spatiotemporal variation characteristics of diffuse PAR are analyzed afterwards, which laid the foundation for further analysis of the impact of diffuse PAR on terrestrial ecosystem productivity.

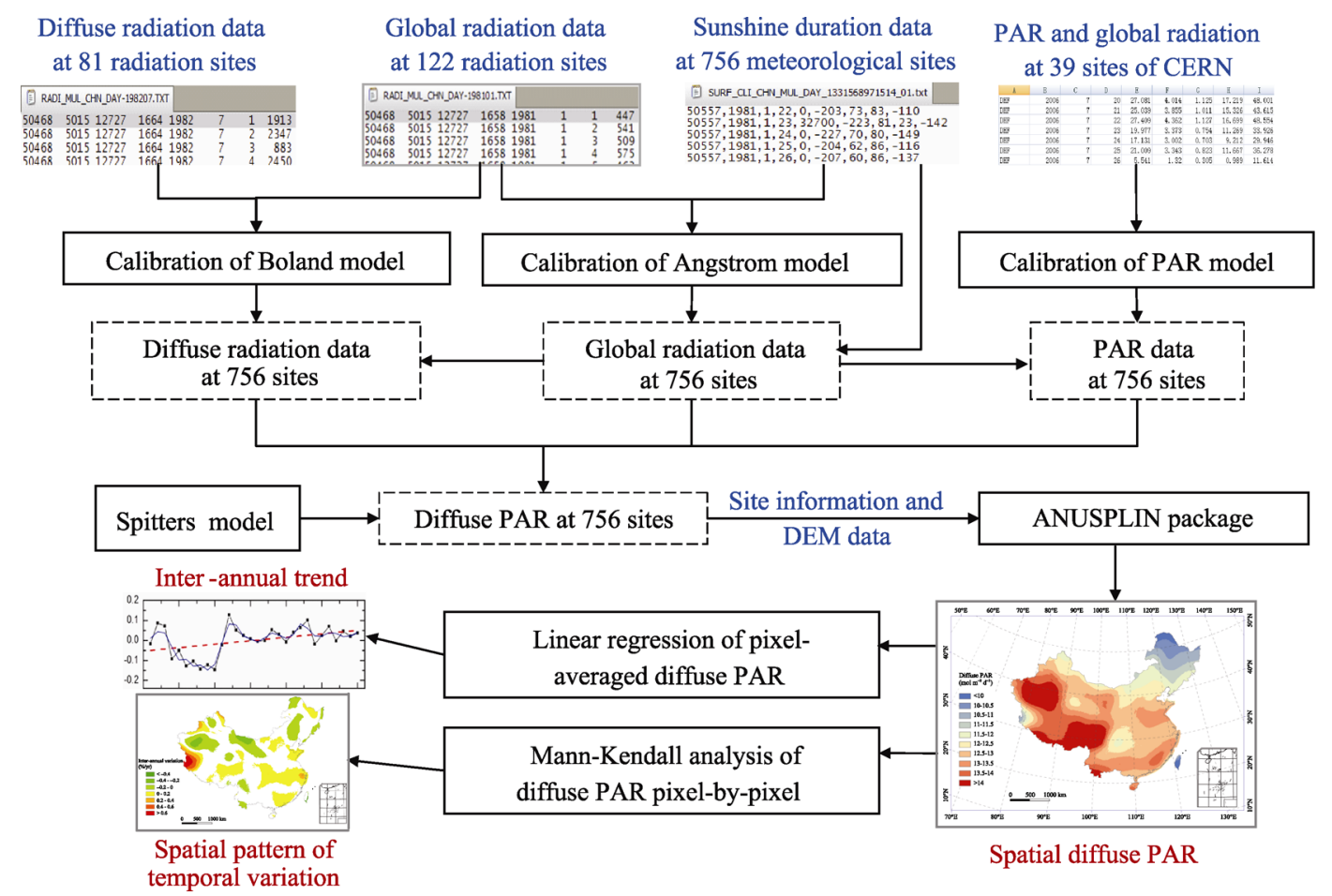

Figure 1 The flowchart of the estimation and spatiotemporal variation analysis of diffuse PAR (the blue font represents the original data, dashed boxes represent the intermediate results, the red font represents the final results, and the solid boxes represent models and methods)

\section{Data and methods}

\subsection{Basic data}

The basic data employed in this study include: (1) daily sunshine duration, global radiation and diffuse radiation data from 1981 to 2010 provided by China Meteorology Administration (CMA) (http://cdc.cma.gov.cn/home.do); (2) daily global radiation and PAR observed in 39 field stations of CERN from 2004 to 2010 (http://www.cerndata.ac.cn/); (3) DEM (Digital Elevation Model) data acquired from Institute of Geographic Sciences and Natural Resources Research, Chinese Academy of Sciences. Sunshine duration is observed from 756 meteorological sites; global radiation is observed at 122 sites; due to the adjustment of radiation stations in 1993, diffuse radiation observation sites reduced from over 70 to 17 in 1993, so there are 81 sites that have at least one year diffuse radiation data during 1981-2010. The distribution of observation sites is shown in Figure 2. 


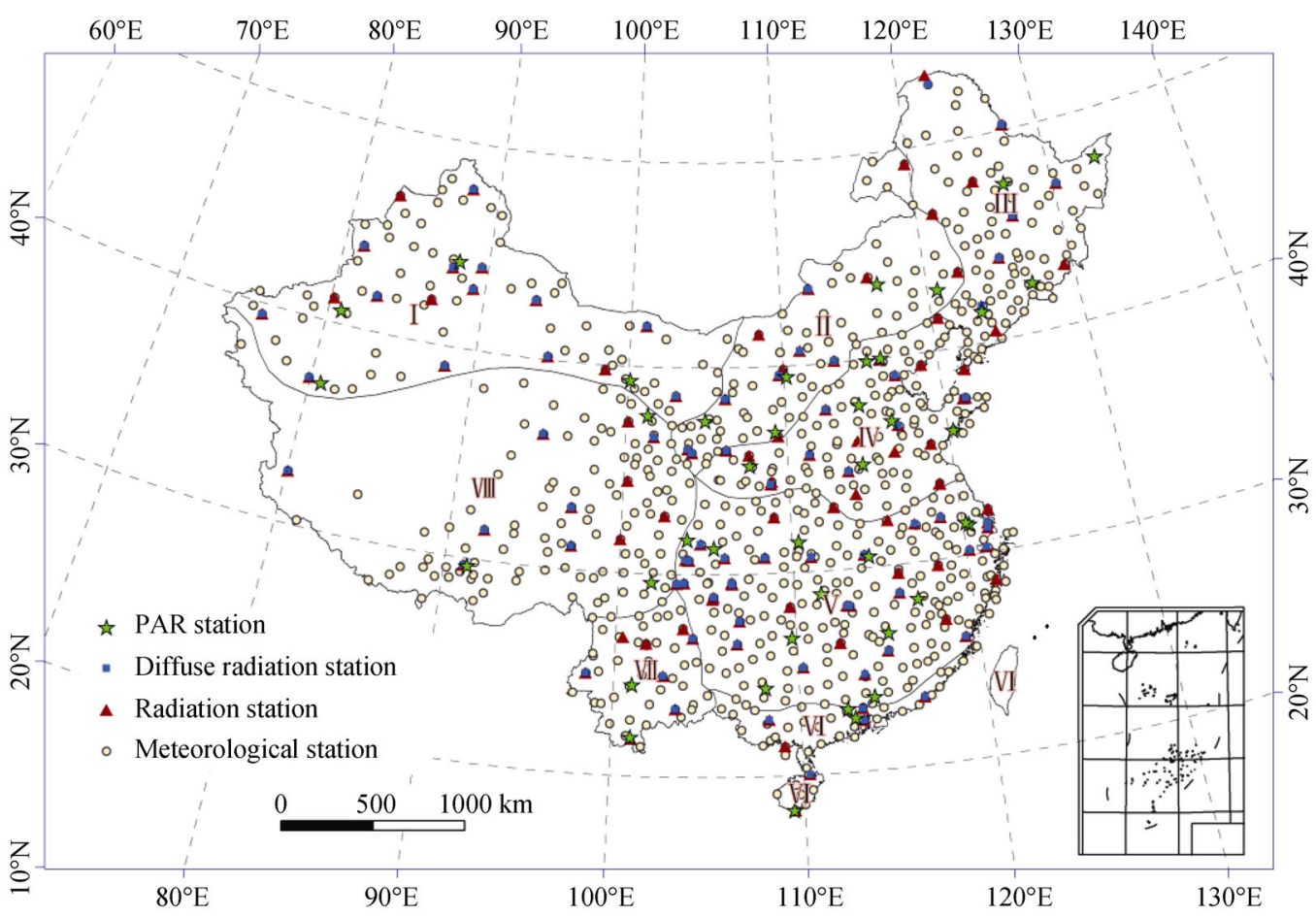

Figure 2 Distribution of meteorological stations, radiation stations and CERN stations (I. Northwest China; II. Inner Mongolia; III. Northeast China; IV. North China; V. Central China; VI. South China; VII. Southwest China; VIII. Qinghai-Tibet Plateau)

\subsection{Calculation of diffuse PAR}

There are few diffuse PAR observation sites in China, so diffuse PAR needs to be estimated using Spitters model based on PAR and diffuse radiation data. However, since the observation sites of PAR and diffuse radiation are sparse in China, we employ the empirical relationships between global radiation and sunshine duration, diffuse radiation and global radiation, PAR and global radiation to expand the observation data of global radiation, diffuse radiation and PAR respectively. In this case, the estimation of diffuse PAR consists of the following four steps (Figure 1).

(1) The expansion of global radiation

We use Angstrom model (Angstrom, 1924) (Equation 1) to extend global radiation. Firstly, the global radiation and sunshine duration observed from 122 radiation sites are utilized to estimate the parameters of Angstrom model. Then the global radiation data of 756 meteorological sites can be derived using the parameterized Angstrom model and the sunshine duration data of 756 sites (Ren et al., 2013).

$$
k_{t}=\frac{Q}{Q^{\prime}}=a+b \frac{n}{N}
$$

where $k_{t}$ is clearness index, $Q$ is global radiation, $Q^{\prime}$ is extraterrestrial radiation, $n$ is actual sunshine duration, $N$ is possible sunshine duration, and the values of coefficients $a$ and $b$ are referred to Ren et al. (2013).

(2) The expansion of diffuse radiation 
Diffuse radiation is calculated using Boland model (Boland et al., 2001, 2008) (Equation 2). We first use global radiation and diffuse radiation data, simultaneously measured in radiation stations, to parameterize the Boland model, and then combine with the global radiation data obtained in the previous step to get the diffuse radiation data of 756 sites (Ren et al., 2013).

$$
k_{d}=\frac{Q_{d}}{Q}=\frac{1}{\exp \left(c+d \cdot k_{t}\right)}
$$

where $k_{d}$ is the diffuse fraction of global radiation, $Q_{d}$ is diffuse radiation, and the values of parameters $c$ and $d$ are referred to Ren et al. (2013).

(3) The expansion of PAR

We employ the method described by Zhu et al. (2010) (Equation 3) to expand PAR data from 39 sites to 756 sites. Firstly, we utilize the PAR and global radiation data measured from the 39 field sites of CERN to estimate the PAR model parameters, and then employ the extended global radiation data and optimized PAR model to estimate PAR.

$$
\eta=\frac{P A R}{Q}=e+f \ln \left(k_{t}\right)
$$

where $\eta$ is photosynthetically active coefficient, $P A R$ is photosynthetically active radiation, and $e$ and $f$ are undetermined coefficients.

(4) The estimation of diffuse PAR

The Spitters model (Spitters et al., 1986) (Equation 4) is applied to calculate diffuse PAR of over 700 sites in China. Under clear skies, the diffuse fraction of PAR (hereinafter called diffuse PAR fraction) is bigger than the diffuse fraction of global radiation (hereinafter called diffuse fraction), as shown in Equation 4.

$$
k_{P A R_{-} d}=\frac{P A R_{d}}{P A R}=\left[1+0.3 \cdot\left(1-k_{d}\right)^{2}\right] \cdot k_{d}
$$

where $k_{P A R_{-} d}$ is diffuse PAR fraction and $P A R_{d}$ is diffuse PAR.

Due to the highly heterogeneous topography and climate of China, we estimate model parameters for Northwest China, Inner Mongolia, Northeast China, North China, Central China, South China, Southwest China, and Qinghai-Tibet Plateau separately according to Chinese Physical Geography Division (Zhao, 1997), considering the distribution of observation sites and the regional differences. Each region has at least 2 PAR observation sites, 5 diffuse radiation measurement sites and 7 global radiation observation sites.

\subsection{Spatialization of diffuse PAR}

ANUSPLIN software package (Hutchinson, 2001) is used to interpolate monthly diffuse PAR data in China with $10 \mathrm{~km}$ spatial resolution from 1981 to 2010 . Firstly, daily diffuse PAR is scaled to monthly data and DEM is resampled to $10 \mathrm{~km}$ resolution using ArcGIS software. Secondly, three-dimensional spline is selected to interpolate monthly diffuse PAR, with longitude and latitude as independent variables and altitude as covariate. The specific process of the spatial interpolation is shown is Figure 3. In the end, map algebra implemented in ArcGIS is employed to compute annual average spatial data of diffuse PAR.

\subsection{Spatiotemporal variation analysis of diffuse PAR}

The spatial distribution of the diffuse PAR is analyzed using the thematic map function of 
ArcGIS. The temporal variation of diffuse PAR during 1981-2010 is analyzed from two angles, i.e. nationwide average (pixel-averaged) and spatial distribution (pixel-by-pixel). The inter-annual variation trend of nationwide average is computed using linear regression analysis, while the spatial distribution of inter-annual variation rates is derived from Mann-Kendall trend analysis method (Wei, 1999; Wang and Liang, 2006). The detailed description of the Mann-Kendall method has been documented by Zhu et al. (2010) and Ren et al. (2013).

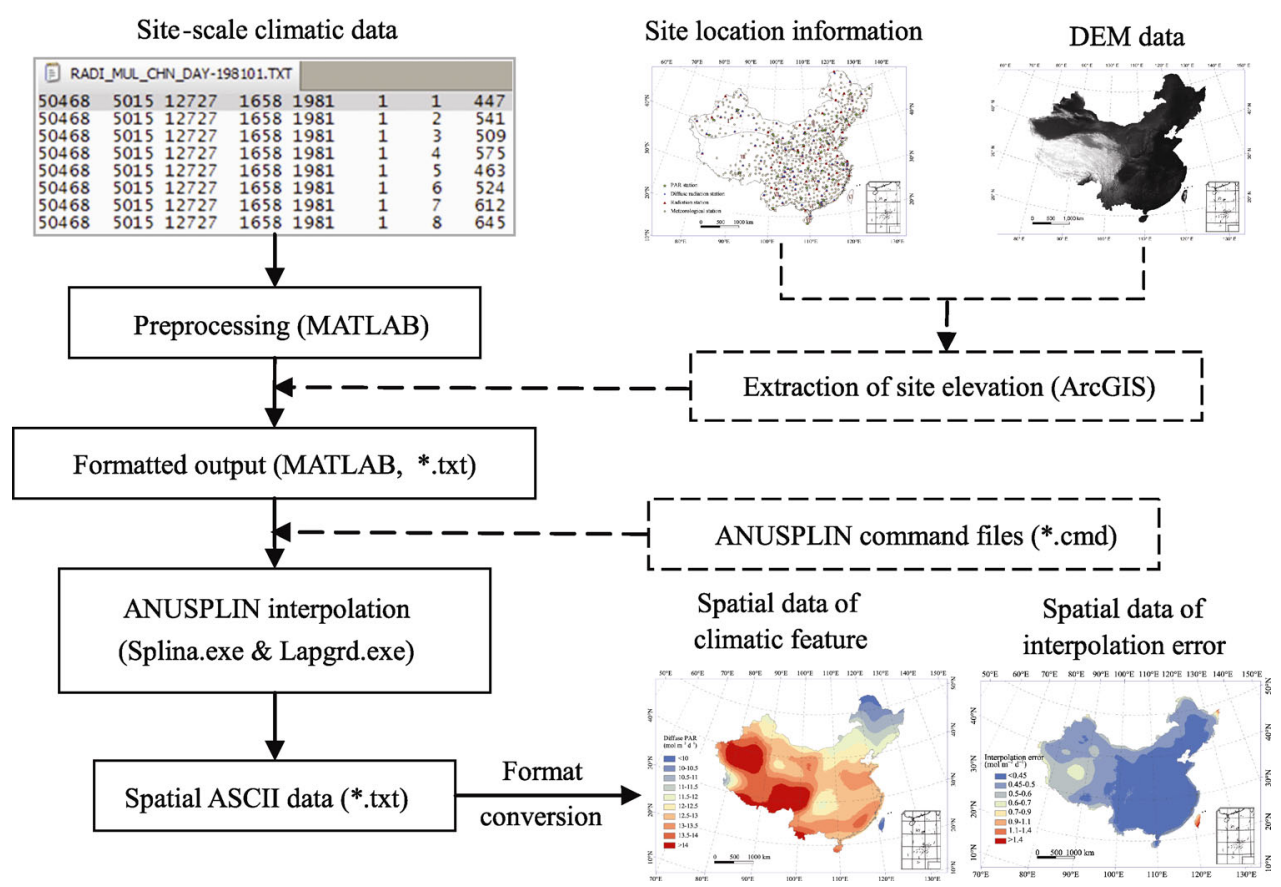

Figure 3 The flowchart of the spatialization of diffuse PAR using ANUSPLIN software

\section{Results}

\subsection{Parameterization and validation of the diffuse PAR estimation}

The Angstrom model, Boland model and PAR model are parameterized and validated using observation data in the eight regions of China respectively. In order to expand the data, we employ leave-one-out cross validation method to verify the site and time independence of the models (Ren et al., 2013). The parameterization and validation of the Angstrom model and Boland model have been conducted by Ren et al. (2013), and both models performed well in almost all regions of China, only relatively poor on the Qinghai-Tibet Plateau due to the sparse distribution of observation stations. Zhu et al. (2010) reported the estimated parameter values of PAR model but did not give the validation accuracy. Besides, the PAR data used by Zhu et al. (2010) were from 36 field sites of CERN during 2004-2007. In this research, we collected more observation data including 39 field sites of CERN from 2004 to 2010. Therefore, we re-parameterized and validated the PAR model.

Table 1 shows the estimated parameter values of PAR model and the validation results of site and time expansion, including the correlation coefficient $(R)$ and the root mean square error (RMSE). Overall, the model performs well in almost all regions of China, with $R$ more 
than 0.97 and $R M S E$ less than $3.5 \mathrm{~mol} \mathrm{~m}^{-2} \mathrm{~d}^{-1}$ in almost all cases. The model performance in Southwest China is slightly poor, probably because the field sites of CERN are relatively sparse in this region (Figure 2). The estimated parameter values are very close to the values reported by Zhu et al. (2010), and the small differences may be caused by the differences of utilized observation data.

Table 1 The results of the calibration and validation of PAR model in different regions across China

\begin{tabular}{|c|c|c|c|c|c|c|c|c|}
\hline $\begin{array}{c}\text { Estimated values and } \\
\text { validation of parameters }\end{array}$ & $\begin{array}{l}\text { Northwest } \\
\text { China }\end{array}$ & $\begin{array}{c}\text { Inner } \\
\text { Mongolia }\end{array}$ & $\begin{array}{l}\text { Northeast } \\
\text { China }\end{array}$ & $\begin{array}{l}\text { North } \\
\text { China }\end{array}$ & $\begin{array}{c}\text { Central } \\
\text { China }\end{array}$ & $\begin{array}{l}\text { South } \\
\text { China }\end{array}$ & $\begin{array}{l}\text { Southwest } \\
\text { China }\end{array}$ & $\begin{array}{c}\text { Qinghai-Tibet } \\
\text { Plateau }\end{array}$ \\
\hline$e$ & 0.39 & 0.38 & 0.35 & 0.35 & 0.36 & 0.38 & 0.36 & 0.40 \\
\hline$f$ & -0.06 & -0.06 & -0.06 & -0.07 & -0.07 & -0.02 & -0.04 & -0.03 \\
\hline Site expansion- $R$ & 0.99 & 0.99 & 0.97 & 0.98 & 0.98 & 0.98 & 0.92 & 0.98 \\
\hline $\begin{array}{l}\text { Site expansion- } \\
R M S E\left(\mathrm{~mol} \mathrm{~m}^{-2} \mathrm{~d}^{-1}\right)\end{array}$ & 2.29 & 2.49 & 3.41 & 2.96 & 2.89 & 3.29 & 4.15 & 2.58 \\
\hline Time expansion- $R$ & 0.99 & 0.99 & 0.97 & 0.98 & 0.98 & 0.99 & 0.97 & 0.99 \\
\hline $\begin{array}{l}\text { Time expansion- } \\
R M S E\left(\mathrm{~mol} \mathrm{~m}^{-2} \mathrm{~d}^{-1}\right)\end{array}$ & 2.15 & 2.31 & 3.17 & 2.83 & 2.85 & 2.76 & 3.54 & 2.40 \\
\hline
\end{tabular}

\subsection{Spatial patterns of diffuse PAR and its interpolation error}

The spatial distribution of diffuse PAR averaged from 1981 to 2010 is inhomogeneous across China. In general, the diffuse PAR is lower in the northeast and higher in the south and west (Figure 4). The annual diffuse PAR over China ranges from $6.66 \mathrm{~mol} \mathrm{~m}^{-2} \mathrm{~d}^{-1}$ to $15.27 \mathrm{~mol} \mathrm{~m}^{-2} \mathrm{~d}^{-1}$, with the average value of $12.85 \mathrm{~mol} \mathrm{~m}^{-2} \mathrm{~d}^{-1}$. Northeast China and

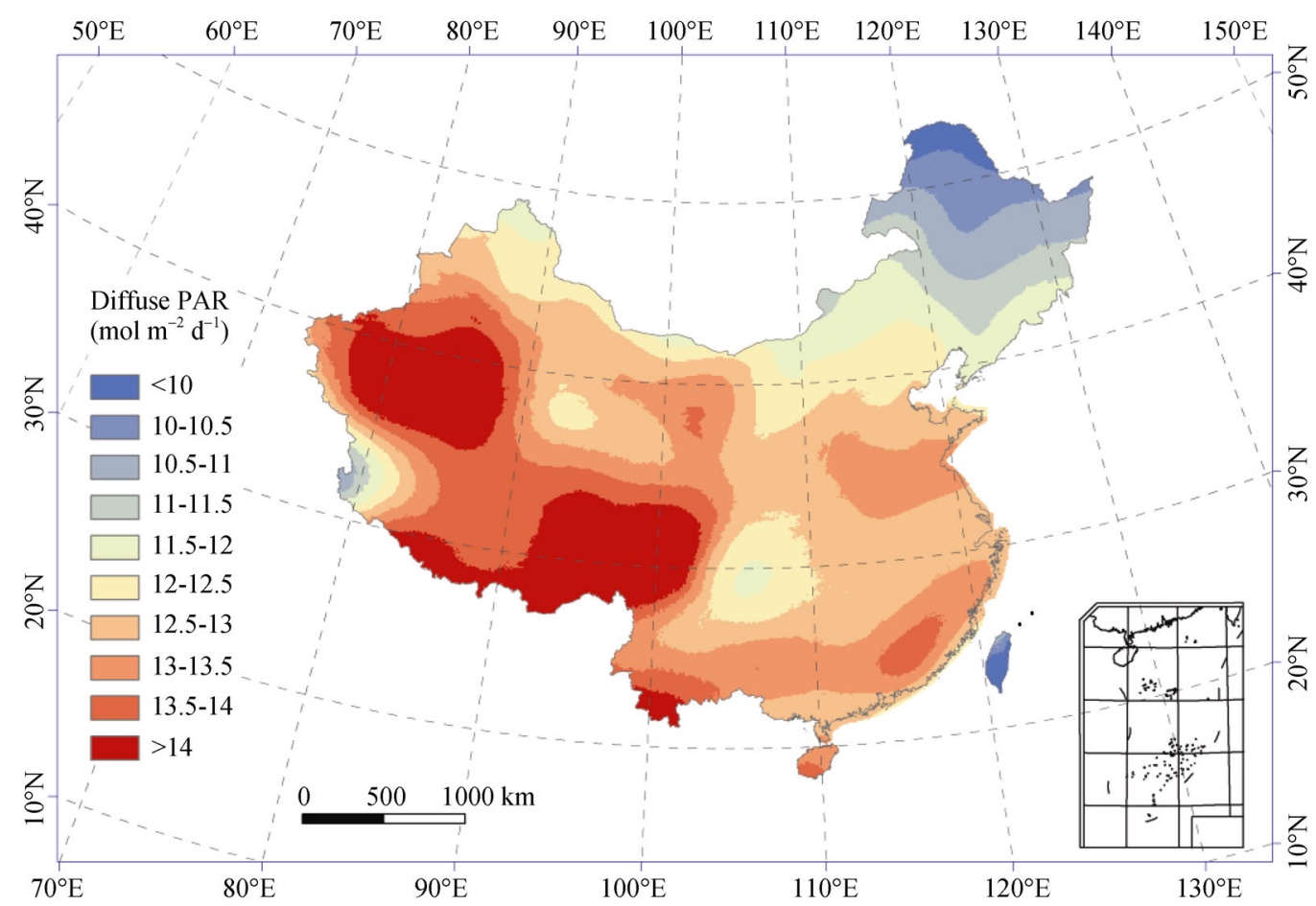

Figure 4 Spatial distribution of perennial average of diffuse PAR in China during 1981-2010 $\left(\mathrm{mol} \mathrm{m}^{-2} \mathrm{~d}^{-1}\right)$ 
Inner Mongolia have relatively low values, with a range of $6.66-12 \mathrm{~mol} \mathrm{~m}^{-2} \mathrm{~d}^{-1}$, while the Southwest China, South China and North China have relatively high values, ranging from 12 $\mathrm{mol} \mathrm{m} \mathrm{m}^{-1}$ to $15.27 \mathrm{~mol} \mathrm{~m}^{-2} \mathrm{~d}^{-1}$. The distribution of diffuse PAR in Northwest China, Qinghai-Tibet Plateau and Central China are more complex. In Northwest China, the eastern part has lower values than the western part. For the Qinghai-Tibet Plateau, there are relatively low values in the northern and western parts. The Sichuan Basin is a low value center of the Central China. The spatial distribution characteristics of diffuse PAR are very similar to those of diffuse radiation reported by Ren et al. (2013).

Figure 5 shows the spatial distributions of seasonal diffuse PAR averaged over recent 30 years. The seasons, i.e. spring, summer, autumn and winter, are represented by April, July, October and January respectively in this study. The diffuse PAR in summer is the largest with average value of $18.09 \mathrm{~mol} \mathrm{~m}^{-2} \mathrm{~d}^{-1}$, followed by the average value of $15.48 \mathrm{~mol} \mathrm{~m}^{-2} \mathrm{~d}^{-1}$ in spring. Autumn and winter have the minimum diffuse PAR, with nationwide average value of $10.41 \mathrm{~mol} \mathrm{~m}^{-2} \mathrm{~d}^{-1}$ and $7.39 \mathrm{~mol} \mathrm{~m}^{-2} \mathrm{~d}^{-1}$ respectively. The spatial patterns of seasonal diffuse PAR in autumn and winter are very similar, consistent with that of annual average distribution (Figures 4, 5c and 5d); while the spatial patterns of seasonal diffuse PAR in spring and summer are quite distinct from the annual average distribution (Figures 4, 5a and $5 b)$.

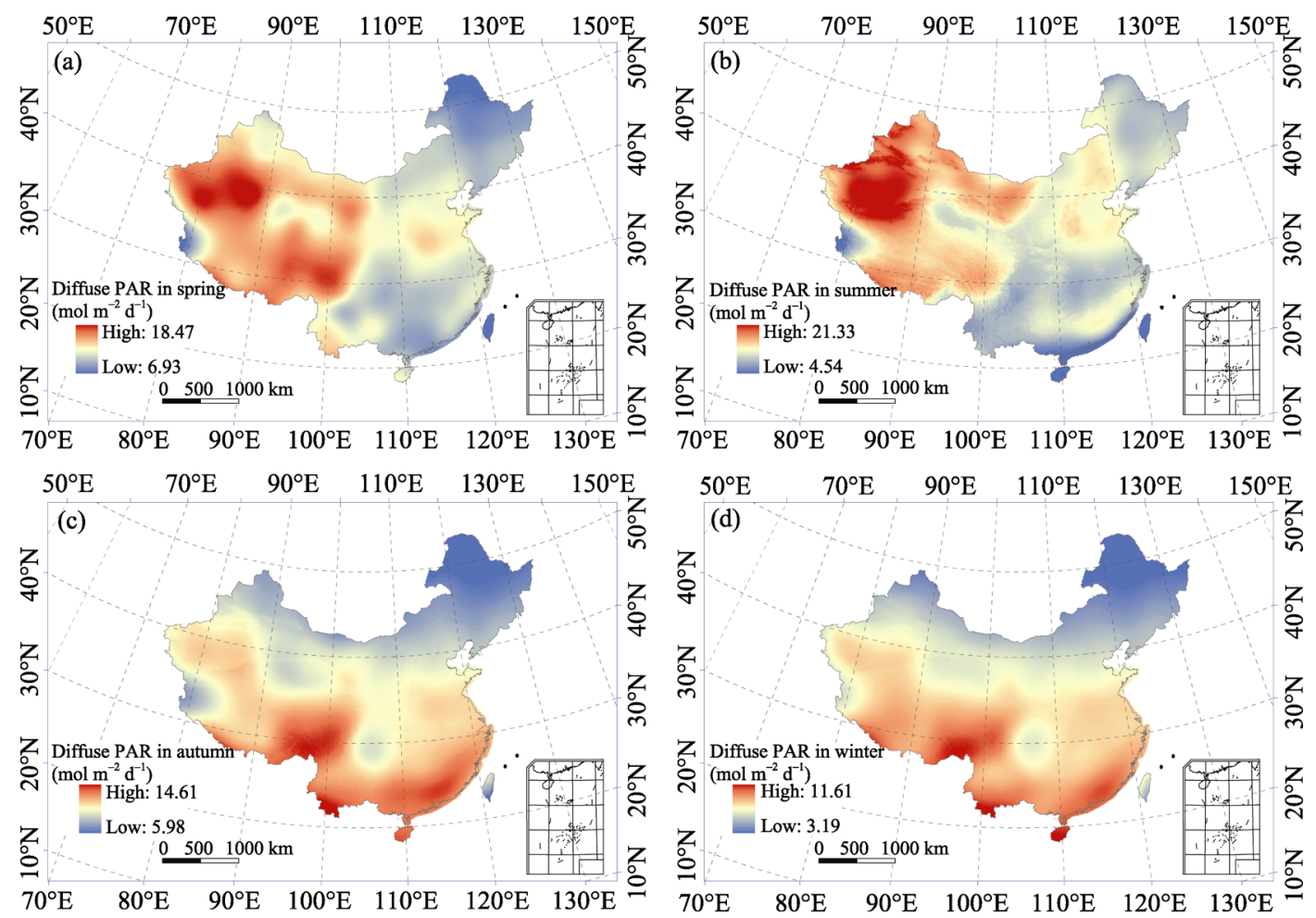

Figure 5 Spatial distributions of perennial average of seasonal diffuse PAR in China during 1981-2010 (a, b, c and $\mathrm{d}$ represent spring, summer, autumn and winter; mol $\mathrm{m}^{-2} \mathrm{~d}^{-1}$ )

ANUSPLIN software can not only interpolate the climatic features but also generate the spatial data of interpolation error (Hutchinson, 2001). Figure 6 displays the spatial distribu- 


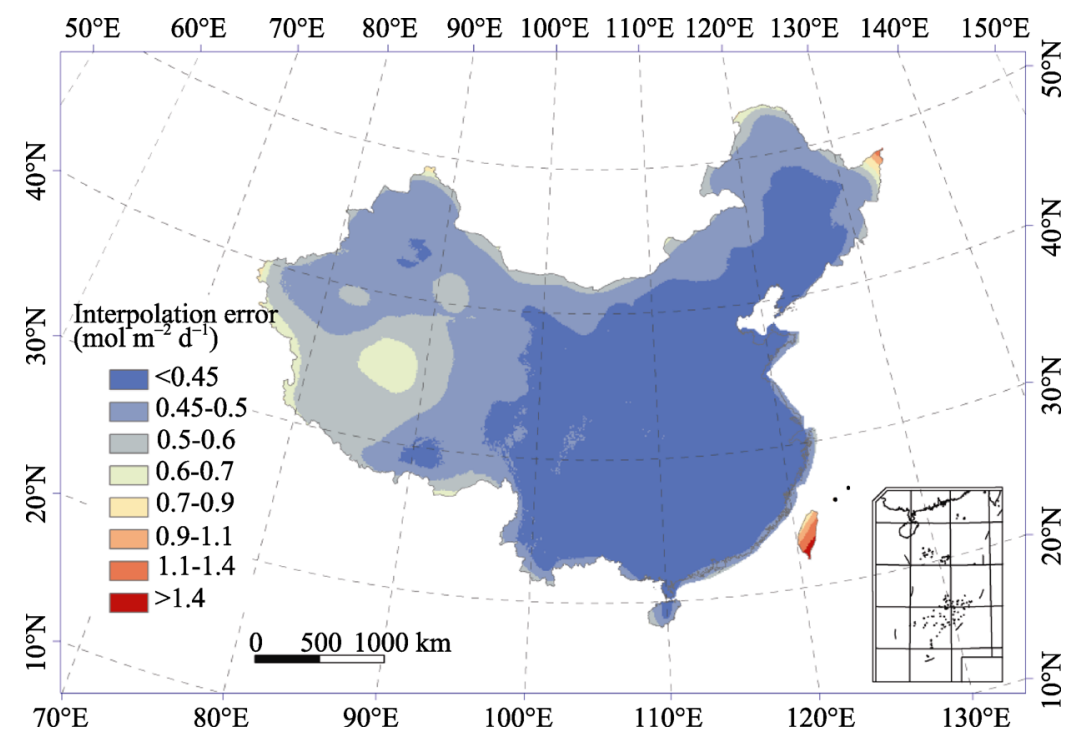

Figure 6 Spatial distribution of perennial average prediction standard errors of diffuse PAR in China during $1981-2010\left(\mathrm{~mol} \mathrm{~m}^{-2} \mathrm{~d}^{-1}\right)$

tion of the diffuse PAR interpolation error averaged over recent 30 years. The range of the interpolation error is between $0.43 \mathrm{~mol} \mathrm{~m}^{-2} \mathrm{~d}^{-1}$ and $1.81 \mathrm{~mol} \mathrm{~m}^{-2}$ $\mathrm{d}^{-1}$, with mean error at $0.47 \mathrm{~mol} \mathrm{~m}^{-2} \mathrm{~d}^{-1}$ and mean relative error at $3.66 \%$. The interpolation error in the northwestern part of the Qinghai-Tibet Plateau is relatively large, probably because the meteorological stations here are very limited (see Figure 2).

\subsection{Inter-annual variation of diffuse PAR}

The long-time series of annual and seasonal pixel-averaged diffuse PAR are derived using map algebra in ArcGIS, and then the inter-annual variation trends are analyzed through linear regression method (Figure 7 and Table 2). There is a slow increasing trend in annual diffuse PAR during 1981 to 2010 and the average increasing amplitude is $0.03 \mathrm{~mol} \mathrm{~m}^{-2} \mathrm{~d}^{-1} / 10 \mathrm{a}$ (Figure $7 \mathrm{a}$ and Table 2). However, there is an obvious decreasing trend during 1981 to 1990 ,

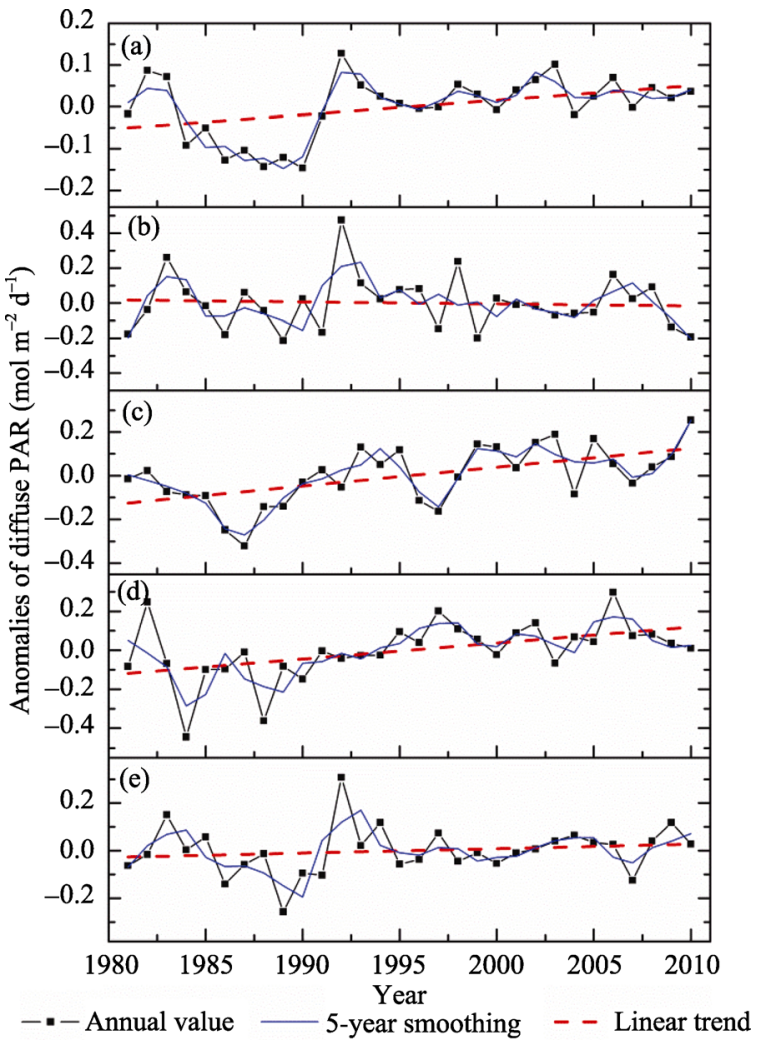

Figure 7 Anomalies of annual and seasonal average diffuse PAR averaged all over China from 1981 to 2010 (a denotes annual average diffuse PAR; b, c, d and e denote seasonal average diffuse PAR of spring, summer, autumn and winter respectively; $\mathrm{mol} \mathrm{m}^{-2} \mathrm{~d}^{-1}$ ) 
and abnormally high values are observed in 1982 and 1983. The diffuse PAR increases dramatically in 1991 and reaches the highest value in 1992.

The diffuse PAR in all seasons shows an upward trend except spring, and only summer and autumn have statistically significant uptrends (Figures $7 \mathrm{~b}$-e and Table 2). The increasing amplitude of diffuse PAR in summer is $0.09 \mathrm{~mol} \mathrm{~m}^{-2} \mathrm{~d}^{-1} / 10 \mathrm{a}$, which is the largest among all seasons, and the increasing amplitude in autumn is $0.08 \mathrm{~mol} \mathrm{~m}^{-2} \mathrm{~d}^{-1} / 10 \mathrm{a}$. The diffuse PAR variations in these two seasons play the most important role in annual diffuse PAR variation during recent 30 years. The diffuse PAR shows a slightly upward trend in winter, with the amplitude at $0.02 \mathrm{~mol} \mathrm{~m}^{-2} \mathrm{~d}^{-1} / 10 \mathrm{a}$. The variation amplitude in spring is $0.01 \mathrm{~mol} \mathrm{~m}^{-2} \mathrm{~d}^{-1} / 10 \mathrm{a}$, which is a weak downtrend.

Table 2 Linear regression coefficients of the anomalies of annual and seasonal average diffuse PAR from 1981 to 2010

\begin{tabular}{cccccc}
\hline & Annual & Spring & Summer & Autumn & Winter \\
\hline Slope & 0.003 & -0.001 & 0.009 & 0.008 & 0.002 \\
Intercept & 12.797 & 15.496 & 17.961 & 10.287 & 7.363 \\
$R$ & $0.413^{*}$ & 0.066 & $0.570^{*}$ & $0.478^{*}$ & 0.158 \\
\hline
\end{tabular}

* Significant at $\alpha=0.05$

\subsection{Spatial distribution of the inter-annual variation of diffuse PAR}

The spatial distribution of diffuse PAR inter-annual variability during 1981 to 2010 is derived using Mann-Kendall trend analysis method (pixel-by-pixel) across China. From Figure 8 , we can see that the inter-annual variability has significant spatial heterogeneity, generally increasing in the southern part and decreasing in the northern part (Figure 8). The whole eastern part of China presents an uptrend except the northeastern part. There is an obvious upward trend in the Tianshan Mountains and distinct downward trends in the Junggar Basin

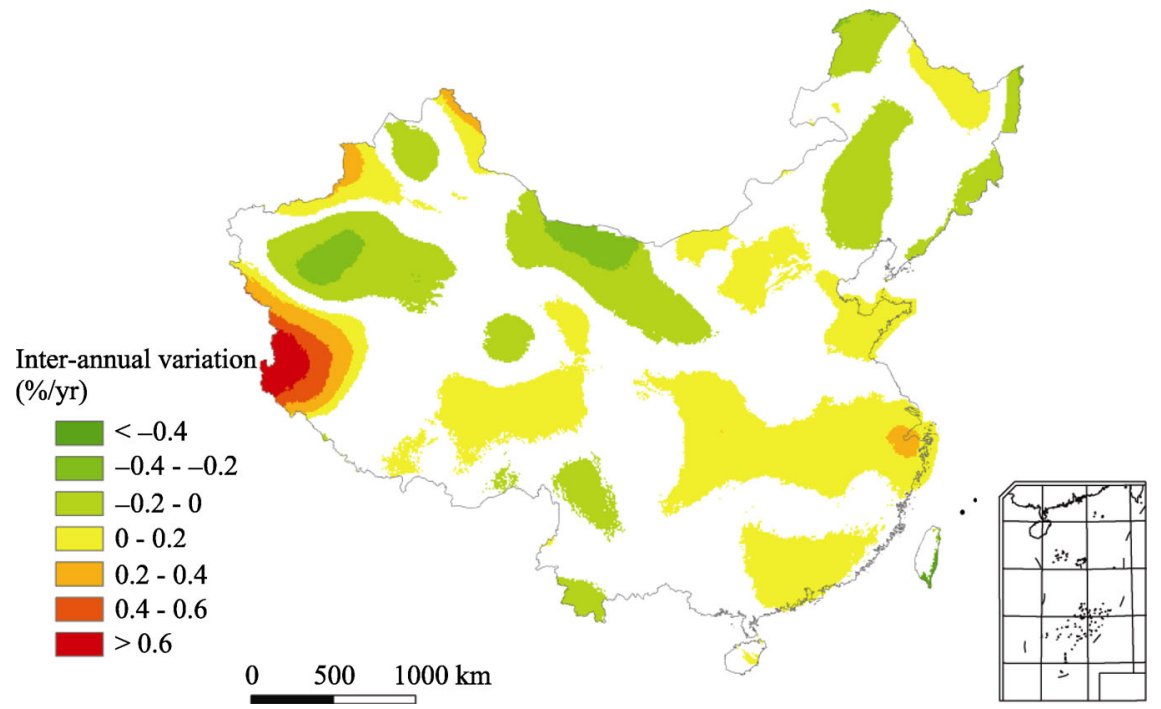

Figure 8 Spatial distribution of the variation rates of annual average diffuse PAR in China from 1981 to 2010 (Blank areas denote that there are no statistically significant trends; \% per year) 
and Tarim Basin. The northern part of the Hexi Corridor also shows a decreasing trend. The Qinghai-Tibet Plateau shows a clearly increasing trend except the southeast foot and Qaidam Basin. As for Inner Mongolia, the middle part shows an uptrend, quite distinct from the other parts. The annual diffuse PAR in North China, Central China and South China are increasing during recent 30 years, particularly evident in Shandong Peninsula, Guangdong Province and the middle and lower reaches of the Yangtze River.

In addition to the regional differences (Figure 8), the temporal variability of diffuse PAR in China during the recent 30 years also presents significant seasonal differences (Figure 9). In spring, downtrend is the dominant variation trend. When it comes to summer and autumn, the area with increasing trend exceeds that with a decreasing trend, indicating an overall uptrend of diffuse PAR in China. In winter, the area with uptrend is slightly larger than that with downtrend, indicating the presence of a weak uptrend across China. These are consistent with the results presented in Section 3.3.
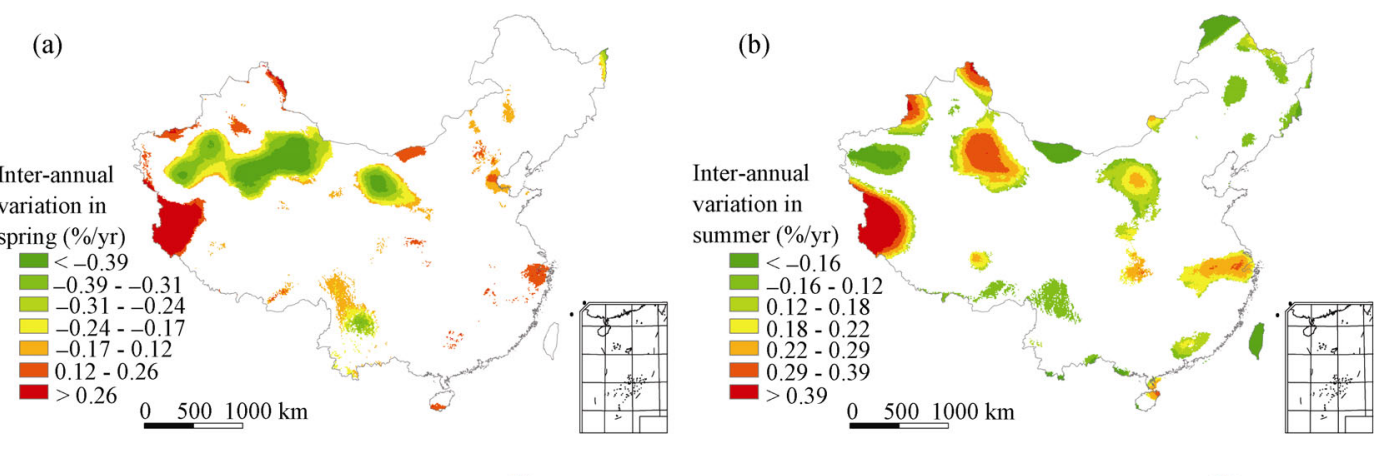

(9)

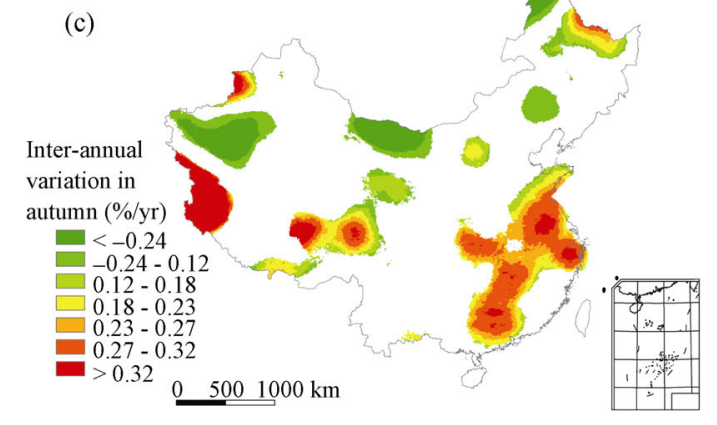

(d)

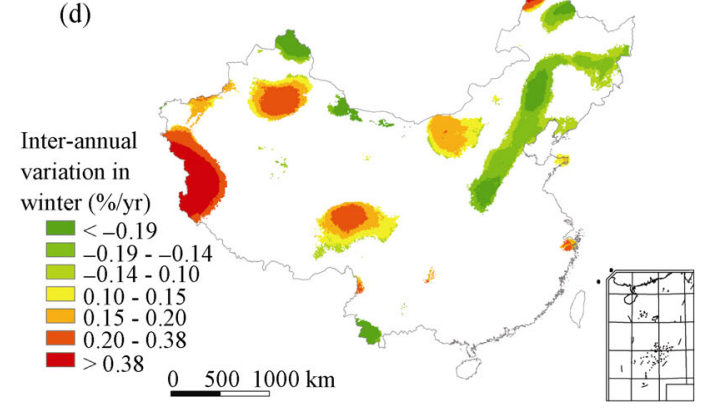

Figure 9 Spatial distribution of variation rates of seasonal average diffuse PAR in China from 1981 to 2010 (Blank areas denote that there are no statistically significant trends; a, b, c and d denote spring, summer, autumn and winter; \% per year)

\section{Discussion}

The scattering particles in the atmosphere can be divided into two kinds. The first one is molecules of nitrogen, oxygen and other gases with diameters less than the wavelength of solar radiation (Rayleigh scattering). The degree of scattering is inversely proportional to the fourth power of the wavelength. The scattering is mainly in visible light, especially in the blue and violet spectrums. The other one is clouds whose diameter is larger than the wavelength of solar radiation, and the degree of scattering is almost the same in different 
spectrums of solar radiation (Spitters et al., 1986; He, 1988). Therefore, under overcast skies, solar radiation is mainly scattered by clouds, thereby making the diffuse fraction of PAR $(400-700 \mathrm{~nm})$ very close to the diffuse fraction of global radiation $(300-3000 \mathrm{~nm})$. While under clear skies, solar radiation is mainly scattered by gas molecules, hence, the diffuse PAR fraction is greater than the diffuse fraction (Spitters et al., 1986; Jacovides et al., 2010). This is the theoretical basis of the Spitters model, indicating that the estimation of diffuse PAR using this model is reasonable (Tsubo and Walker, 2005).

Many factors affect the spatiotemporal variations of diffuse PAR, including extraterrestrial radiation, cloud cover and aerosols (Kanniah et al., 2012). The net effect of these factors on the diffuse PAR is determined by the balance between the reduction of PAR and the increase of diffuse fraction. Therefore, to explore the spatiotemporal variations of diffuse PAR, we need to analyze the spatiotemporal variations of PAR and diffuse fraction. The spatial distribution and inter-annual variation trend of diffuse PAR are very similar to those of diffuse radiation described by Ren et al. (2013). This is likely because diffuse PAR is determined by PAR and diffuse fraction while diffuse radiation is determined by global radiation and diffuse fraction, and the relationship between global radiation and PAR is reflected by photosynthetically active coefficient, which has very small spatiotemporal variations.

As can be seen from the Spitters model, the spatial distribution of diffuse PAR is determined by the spatial distribution of PAR and diffuse fraction. PAR is lower in the eastern and southern parts and higher in the western part of China (Zhu et al., 2010), while diffuse fraction is higher in the eastern and southern parts and relatively lower in the other regions (Ren et al., 2013). The spatial distribution characteristics of diffuse PAR are determined by both the distribution and quantity of PAR and diffuse fraction. PAR decreases in recent 30 years with the amplitude at $0.13 \% / 10 \mathrm{a}$, and Ren et al. (2013) reported that diffuse fraction increased from 1981 to 2010 with the rate of $0.21 \% / 10 \mathrm{a}$. We can see that the uptrend of diffuse fraction is much more significant than the downtrend of PAR, so diffuse PAR shows an uptrend during 1981 to 2010.

The anomalies in 1982, 1983, 1991 and 1992 are probably due to significantly increased aerosols in the atmosphere caused by the volcanic eruptions in April 1982 and June 1991, namely El Chinchon eruption and Pinatubo eruption. The Pinatubo eruption is the strongest volcanic eruption over the last century, and it released about $20 \mathrm{Tg}$ sulphate into the stratosphere, which greatly increased the amount of diffuse radiation in the following 2 years (Mercado et al., 2009). Therefore, the diffuse PAR shows unprecedented increases in 1991 and 1992, and reaches the highest value in 1992 for recent 30 years.

Since there are few diffuse PAR observation stations in China, the diffuse PAR data are usually obtained through estimation. The most commonly used method is multiplying PAR and diffuse fraction of global radiation directly, but the resulting diffuse PAR is just a rough estimate. This paper attempted to provide more reliable diffuse PAR data of China, whereas the biggest shortcoming is that there are no observation data for validation. In the four steps of diffuse PAR estimation flowchart (Figure 1), the first three steps all have been verified and proven to work well. Although the fourth step, i.e. the calculation of diffuse PAR, was not validated using observation data, the Spitters model has been applied and validated in many sites worldwide, which indicated the universality of the model. Therefore, we believe 
that this research is a useful attempt in the acquisition of accurate diffuse PAR data. Although there are uncertainties inevitably in the derived diffuse PAR data, they can still reflect the spatial and temporal variability of diffuse PAR, which can provide basic research data for the quantitative analysis of the impact of diffuse PAR on ecosystem productivity.

\section{Conclusions}

We derived the first set of monthly diffuse PAR data with $10 \mathrm{~km}$ spatial resolution during 1981 to 2010, and analyzed the spatiotemporal variation characteristics. This laid the foundation for quantitative analysis of the effects of diffuse PAR on ecosystem carbon and water cycles, making the regional scale ecosystem modeling more accurate. The main conclusions are as follows:

(1) Although the diffuse PAR data obtained from the Spitters model were not validated using observation data, the two input datasets, i.e. PAR and diffuse fraction, were verified using leave-one-out cross validation method, which validated the accuracy of diffuse PAR indirectly. The spatial distribution and temporal variation of diffuse PAR are very similar to those of diffuse radiation probably due to the similarity of spatiotemporal characteristics of PAR and global radiation.

(2) The spatial pattern of annual diffuse PAR averaged during 1981-2010 was complex and inhomogeneous, generally lower in the northeastern part and higher in the southern and western parts of China. The perennial average value ranges from $6.66 \mathrm{~mol} \mathrm{~m}^{-2} \mathrm{~d}^{-1}$ to 15.27 mol m $\mathrm{m}^{-2}$, with the nationwide average value at $12.85 \mathrm{~mol} \mathrm{~m}^{-2} \mathrm{~d}^{-1}$. And the diffuse PAR is the largest in summer and the smallest in winter.

(3) The nationwide pixel-averaged annual diffuse PAR showed an uptrend during 1981 to 2010, with the increasing amplitude at $0.03 \mathrm{~mol} \mathrm{~m}^{-2} \mathrm{~d}^{-1} / 10 \mathrm{a}$. There is an evident downtrend during the first 10 years, and obvious anomalies are observed in 1982, 1983, 1991 and 1992. The diffuse PAR in all seasons showed increasing trends except spring. The spatial distribution of diffuse PAR changing rate during recent 30 years had clear regional differences, increasing in the south and decreasing in the north.

\section{References}

Angstrom A, 1924. Solar and terrestrial radiation. Quarterly Journal of the Royal Meteorological Society, 50(210): 121-126.

Boland J, Ridley B, Brown B, 2008. Models of diffuse solar radiation. Renewable Energy, 33(4): $575-584$.

Boland J, Scott L, Luther M, 2001. Modelling the diffuse fraction of global solar radiation on a horizontal surface. Environmetrics, 12(2): 103-116.

Cho H K, Jeong M J, Kim J et al., 2003. Dependence of diffuse photosynthetically active solar irradiance on total optical depth. Journal of Geophysical Research-Atmospheres, 108(D9).

Farquhar G D, Roderick M L, 2003. Atmospheric science: Pinatubo, diffuse light, and the carbon cycle. Science, 299(5615): 1997-1998.

Gu L H, Baldocchi D D, Verma S B et al., 2002. Advantages of diffuse radiation for terrestrial ecosystem productivity. Journal of Geophysical Research-Atmospheres, 107(D6): ACL 2-1-ACL 2-23.

Gu L H, Baldocchi D D, Wofsy S C et al., 2003. Response of a deciduous forest to the Mount Pinatubo eruption: Enhanced photosynthesis. Science, 299(5615): 2035-2038.

Gu L H, Fuentes J D, Shugart H H et al., 1999. Responses of net ecosystem exchanges of carbon dioxide to 
changes in cloudiness: Results from two North American deciduous forests. Journal of Geophysical Research-Atmospheres, 104(D24): 31421-31434.

He Q T, 1988. Meteorology. Beijing: China Forestry Press. (in Chinese)

He X Z, Zhou T, Jia G S et al., 2011. Modeled effects of changes in the amount and diffuse fraction of PAR on forest GPP. Journal of Natural Resources, 26(4): 619-634. (in Chinese)

Hutchinson M F, 2001. ANUSPLIN Version 4.2 User Guide. Canberra: Center for Resource and Environmental Studies, the Australian National University.

Jacovides C P, Boland J, Asimakopoulos D N et al., 2010. Comparing diffuse radiation models with one predictor for partitioning incident PAR radiation into its diffuse component in the eastern Mediterranean basin. Renewable Energy, 35(8): 1820-1827.

Jacovides C P, Tymvios F S, Assimakopoulos V D et al., 2007. The dependence of global and diffuse PAR radiation components on sky conditions at Athens, Greece. Agricultural and Forest Meteorology, 143(3/4): 277-287.

Kanniah K D, Beringer J, North P et al., 2012. Control of atmospheric particles on diffuse radiation and terrestrial plant productivity: A review. Progress in Physical Geography, 36(2): 209-237.

Mercado L M, Bellouin N, Sitch S et al., 2009. Impact of changes in diffuse radiation on the global land carbon sink. Nature, 458(7241): 1014-1017.

Ren X L, He H L, Zhang L et al., 2013. Spatiotemporal variability analysis of diffuse radiation in China during 1981-2010. Annales Geophysicae, 31(2): 277-289.

Spitters C J T, Toussaint H A J M, Goudriaan J, 1986. Separating the diffuse and direct component of global radiation and its implications for modeling canopy photosynthesis: 1. Components of incoming radiation. Agricultural and Forest Meteorology, 38(1-3): 217-229.

Sun J S, Zhou G S, 2010. Review of advances in measurements and effects of diffuse radiation on terrestrial ecosystem productivity. Chinese Journal of Plant Ecology, 34(4): 452-461. (in Chinese)

Tsubo M, Walker S, 2005. Relationships between photosynthetically active radiation and clearness index at Bloemfontein, South Africa. Theoretical and Applied Climatology, 80(1): 17-25.

Wang J L, Liang X J, 2006. Nonparametric Statistical Analysis. Beijing: Higher Education Press. (in Chinese)

Wang X P, Guo Y, Wang X Y et al., 2008. Estimating photosynthetically active radiation distribution in maize canopies by a three-dimensional incident radiation model. Functional Plant Biology, 35(9/10): 867-875.

Wei F Y, 1999. Modern Statistical Diagnosis and Forecasting Techniques for Climate. Beijing: China Meteorological Press. (in Chinese)

Wild M, 2009. Global dimming and brightening: A review. Journal of Geophysical Research-Atmospheres, 114(21): D00D16.

Wild M, Gilgen H, Roesch A et al., 2005. From dimming to brightening: Decadal changes in solar radiation at Earth's surface. Science, 308(5723): 847-850.

Zhang M, Yu G R, Zhang L M et al., 2010. Impact of cloudiness on net ecosystem exchange of carbon dioxide in different types of forest ecosystems in China. Biogeosciences, 7(2): 711-722.

Zhang M, Yu G R, Zhuang J et al., 2011. Effects of cloudiness change on net ecosystem exchange, light use efficiency, and water use efficiency in typical ecosystems of China. Agricultural and Forest Meteorology, 151(7): 803-816.

Zhao J, 1997. Atlas for Physical Geography of China. Beijing: Higher Education Press. (in Chinese)

Zhu X D, He H L, Liu M et al., 2010. Spatio-temporal variation of photosynthetically active radiation in China in recent 50 years. Journal of Geographical Sciences, 20(6): 803-817. 